\title{
Ethnic representation in a sample of the literature of applied psychology
}

\author{
Leslie Case \\ University of South Dakota \\ Timothy B. Smith \\ Brigham Young University, tbs@byu.edu
}

Follow this and additional works at: https://scholarsarchive.byu.edu/facpub

Part of the Counseling Psychology Commons

\section{Original Publication Citation}

Case, L., \& Smith, T. B. (2000). Ethnic representation in a sample of the literature of applied psychology. Journal of Consulting and Clinical Psychology, 68, 1107-1110.

\section{BYU ScholarsArchive Citation}

Case, Leslie and Smith, Timothy B., "Ethnic representation in a sample of the literature of applied psychology" (2000). Faculty Publications. 2030.

https://scholarsarchive.byu.edu/facpub/2030

This Peer-Reviewed Article is brought to you for free and open access by BYU ScholarsArchive. It has been accepted for inclusion in Faculty Publications by an authorized administrator of BYU ScholarsArchive. For more information, please contact ellen_amatangelo@byu.edu. 


\section{Running Head: MULTICULTURAL REPRESENTATION}

Case, L., \& Smith, T. B. (2000). Ethnic representation in a sample of the literature of applied psychology. Journal of Consulting and Clinical Psychology, 68, 1107-1110.

Ethnic Representation in a Sample of

the Literature of Applied Psychology

Leslie Case

University of South Dakota

Timothy B. Smith

Brigham Young University 


\begin{abstract}
A number of authors have raised concerns over the external validity of psychological research. This study examined the extent to which empirical articles include human participants from diverse ethnic backgrounds. Articles published over a five-year period in 14 selected journals representing clinical, counseling, and school psychology were examined, and the ethnic compositions of the articles’ participant pools were recorded. Of the 2536 articles coded, only $61.2 \%$ indicated the ethnicity of the participants. For those articles, the ethnic compositions approximated U.S. Census estimates, with the exception of an overrepresentation of African Americans and an underrepresentation of Hispanic/Latino Americans. The results imply that although the field is apparently adequately recruiting English speakers, representation of nonEnglish speakers should be increased. To further enhance the external validity of psychological research, ethnicity of participants should not only be specified but be analyzed in relation to the results of a study.
\end{abstract}


Talking the Talk or Walking the Walk?

Ethnic Representation in a Sample of the Literature of Applied Psychology

In his parting editorial, former Journal of Consulting and Clinical Psychology editor Larry Beutler (1996) emphasized the importance of detailed reporting of demographic information of human participants. He encouraged efforts to reliably measure and analyze demographic constructs, and he cited a statement developed by the National Institute of Mental Health's Editor's Consortium that clearly spells out the need to do so:

Not only is the complete description of a study sample central to the scientific goals of sound and replicable research, but also these variables may affect the generalizability of the research findings. This information is necessary for the meaningful interpretation of findings from a particular study. Moreover, the availability of this information provides the methodological basis for determining the extent to which findings depend upon individual and socio-demographic characteristics of the sample. (pp. 846-847) Reporting and analyzing sample composition is "good science," a standard to be met in the interest of external validity.

Of course, representative sampling is essential to external validity (Babbie, 1998). Because psychological research must be relevant and appropriate for individuals from diverse ethnic backgrounds (Sue, 1999), researchers must use samples that adequately represent diverse populations. Published research often determines what will be taught and which mental health interventions will be used. But if the results of research are not examined in relation to the ethnic composition of the participants, the value of such research is limited, and what it advocates may even prove harmful (Sue \& Sue, 1999). 
The majority of psychotherapy research has been conducted with predominantly middle-class White Americans (Alvidrez, Azocar, \& Miranda, 1996; Graham, 1992). As a result, limited data are available to help researchers and practitioners ensure that appropriate services are provided to clients from different backgrounds (Miranda, 1996). Few psychotherapy studies include representative numbers of people of color in their samples, despite the fact that the proportion of people of color is increasing in the United States (Alvidrez et al., 1996). Such traditional patterns reflect cultural biases within the field, and some observers imply that underrepresentation of people of color in psychological research may be a product of institutionalized racism (Sue \& Sue, 1999). Although likely unintentional, such misrepresentation clearly compromises the quality of the field.

\section{Multicultural Publication Content}

Previous studies on the inclusiveness of psychological research have noted the lack of journal articles focused specifically on people of color. For example, Graham (1992) found that only 3.6\% of articles in 6 journals published by the American Psychological Association (APA) between 1970 and 1989 had content specific to African Americans. Furthermore, she noted a decline in such articles over time, from 5.2\% during the period 1970-1974 to $2.0 \%$ during the period 1985-1989. Similarly, Santos de Barona (1993) reported an average annual decline of 1.5 articles on people of color in 11 APA journals over 21 years. Proportions of journal content specific to people of color as low as $1.3 \%$ have been reported by reviewers (Iwamasa \& Smith, 1996).

Because a disproportionately small percentage of the research literature focuses on concerns specific to people of color, an implicit (albeit incorrect) assumption may be that such a focus is not necessary: As long as people of color are adequately represented in the research samples, 
then the results should generalize to those populations. However, although several studies have examined the content of research with respect to its focus on people of color, no examination has scrutinized the degree to which people of color are actually represented in research samples.

\section{Difficulties Achieving Representative Samples}

Researchers have given varied reasons for not including people of color in their studies. For some, the unwillingness to investigate topics that are socially relevant but not "politically correct” is problematic (Buetler, Brown, Crothers, Booker, \& Seabrook, 1996). For others, the practical difficulties and higher expenses incurred in gaining access to certain populations serve as deterrents (Sue, 1999) because people of color are underrepresented in the university and mental health settings from which researchers typically recruit participants (Hough et al., 1987; Santos de Barona, 1993; Snowden \& Cheung, 1990; Wells, Hough, Golding, Burnam, \& Karno, 1987). Distrust of research among some people of color is another factor to consider because research has often been misused in regard to these groups (Maultsby, 1982; Sue \& Sue, 1999). For example, historically research has been used as a justification for slavery, as a "scientific" rationale for segregation, or as support for the concept of racial inferiority/superiority (Williams, 1986). Additionally, the stigma that some people of color attach to concepts of mental health and illness may reduce their willingness to become involved in psychological research (Griffith \& Baker, 1993).

Despite the number of reasons given for non-inclusive research, strategies to overcome these difficulties have also been detailed in the literature. For example, techniques that have been used to successfully recruit participants of Hispanic origin for psychological research include incorporating social networking strategies, utilizing face-to-face recruitment, forming professional relationships with community agencies and offering free training to agency 
personnel, advertising in both English and Spanish, providing transportation and childcare, and placing reminder phone calls (e.g., Hooks, Tsong, Henske, Baranowski, \& Levin, 1986). Furthermore, retention can be enhanced through culturally sensitive treatment and by incorporating family members, assessing level of acculturation, and utilizing bilingual staff (Mezzich, Ruiz, \& Munoz, 1999; Miranda, Azocar, Organista, Munoz, \& Lieberman, 1996).

\section{$\underline{\text { Recent Multicultural Emphases }}$}

These recommendations for inclusive recruitment strategies just listed are part of the larger context of the contemporary emphasis on multiculturalism. For example, the American Psychological Association's (APA) training standards have been revised to include provisions for integrating multicultural themes into the curricula of psychology training programs (e.g., Yutrzenka, 1995). Similarly, revisions of ethical codes of the APA (1992), the National Association of School Psychologists (NASP) (NASP, 1997), and the American Counseling Association (ACA) (ACA, 1995) address multicultural issues for researchers and practitioners.

Concerns over the issue of adequate sample representation have also led to changes in the policies of research funding institutions. For example, the National Institutes of Health (NIH) has mandated that women and minority group members be included in all NIH supported research (NIH, 1994). Neither the cost of including diverse populations nor the geographic area of the investigator can be used to rationalize inadequate representation. Such changes are being adopted throughout the field to correct the underrepresentation of minorities in clinical research and to aid the scientific community in producing generalizable research (Miranda, 1996).

\section{A Needed Self-Examination: Scrutinizing Psychology}

Although the field of psychology is certainly "talking the talk" about multiculturalism, is it also "walking the walk"? It is hoped that the recent discourse on multiculturalism in the 
literature of psychology has initiated action. To determine if efforts have been made to adequately represent people of color in empirical research samples, this study examined a sample of literature produced over a recent five-year period. Data from a recent census of the United States were then compared to the percentages of people of color included in the research samples. Based upon the research cited above, it was hypothesized that the overall percentage of people of color among research participants would be less than the percentage represented in census population estimates, and that this underrepresentation would be found for all ethnic minority groups.

\section{Method}

Journals from 1993 to 1997 were chosen to represent the applied sub-disciplines of clinical, counseling, and school psychology based on their classification in the most recent edition of APA's Journals in Psychology (APA, 1997). Journals were not included in this study if they did not focus on service provision, if they had an explicitly international focus, if they represented specific subspecialties, if they were explicitly theoretical, or if they specifically focused on people of color. Table 1 lists the resulting 14 journals selected by sub-discipline.

Within the selected journals, each empirical article with human participants was reviewed. Theoretical articles, program descriptions, book reviews, rebuttals, editorial statements, literature reviews, meta-analyses, film reviews, commemorative award speeches, tributes, and brief reports of two pages or less were not considered in the analyses.

For each article, the ethnic composition of the research sample reported by the authors was recorded. Researchers used various descriptions of the ethnicity of their sample, with most being compatible with the categories of the U. S. Bureau of the Census (1996). However, some authors used a non-descriptive “other," and some studies involved participants from outside the 
United States. Thus eight categories of participants were coded in this study: African American, Hispanic American, Asian American or Pacific Islander, Native American, European American, international, other, and not reported. Studies in which content focused on a specific ethnic group were also noted following examination of the abstract and the method section of the article.

\section{Results}

After the data were coded, a reliability check of the articles was performed by an independent, trained coder. The number of agreements divided by the number of agreements and disagreements yielded a reliability estimate of 99.7\%. Of the 2,536 empirical articles coded, 1,552 (61.2\%) reported the ethnicity of their participant pools. The average reporting rates differed substantially between the individual journals, ranging from $82 \%$ to $33 \%$ (see Table 1).

Across all articles, 54.4\% of research participants were European American, 12.3\% were African American, 4.4\% were Hispanic American, 2.1\% were Asian American, 0.8\% were Native American, 22.5\% were international, and 3.4\% were “other.” To facilitate accurate comparison with U.S. Census data, the "other” and "international” categories were subsequently removed from the analyses (Table 2). When the resulting percentages from all studies were compared to those of the 1996 U.S. Census data, significant differences were found $\left(\chi^{2}=46.91\right.$, $\mathrm{p}<.001)$. Specifically, the research samples typically overrepresented African Americans $(\underline{\mathrm{z}}=4.68, \mathrm{p}<.001)$ but underrepresented Hispanic Americans $(\underline{\mathrm{z}}=5.21, \mathrm{p}<.001)$ compared to their representation in the general population.

The content of the research studies was also examined to see how many of the studies focused specifically on issues pertinent to people of color. Overall, $7.2 \%$ of the articles focused 
on a specific racial/ethnic group, with $5.2 \%$ focused solely on one group of interest and $2.0 \%$ comparing that group to a Caucasian sample.

\section{Discussion}

In light of recent concerns about the external validity of psychotherapy research (e.g., Sue, 1999; Sue \& Sue, 1999), the purpose of this study was to investigate the current state of participation of people of color in psychological research. Although previous critiques have focused on content relevant to specific ethnic groups (Alvidrez et al., 1996) or on demographic variables report rates (Beutler et al., 1996), this paper is the first to examine a broad range of applied research to determine ethnic specific content, reporting rates, and representation of ethnic groups compared to population estimates.

Contrary to expectations (Graham, 1992), African American participants were actually overrepresented compared to population estimates. This finding seems to indicate that some researchers emphasize recruitment among this group. Research samples also included Asian Americans and Native Americans in proportions similar to population estimates. However, research samples underrepresented Hispanic Americans by about 44\% compared to population estimates.

Although these data do not identify causative factors, the related estimate that about $39 \%$ of people of Hispanic origin living in the U.S. are not fluent in English (U.S. Bureau of Census, 1996) may indicate that researchers fail to use the Spanish language in their recruitment procedures. The field of psychology seems to be "talking the talk" about multiculturalism, but apparently in "English only." Because Hispanic Americans constitute the fastest growing ethnic group in the nation (U.S. Bureau of Census, 1996) and because monolingual Spanish speakers may have greater needs for clinical services than English speakers (Schur \& Albers, 1996), the 
results of this study should serve as a wake up call (or llamada urgente) to the field.

Recommendations for adaptations of mental health care (e.g., Mezzich et al., 1999) and for successful research recruitment and retention (e.g., Hooks et al., 1986) should be seriously considered.

Recognizing the need for enhanced external validity in psychological research (Sue, 1999), it is encouraging to note that $7.2 \%$ of the studies had content specific to an ethnic group. This estimate is notably higher than the proportions found in previous studies, which have ranged between 1.3\% and 5\% (e.g., Graham, 1992; Iwamasa \& Smith, 1996). Support for increasing the quantity of such emic research comes from Triandis (1996), who has argued that work with specific groups is the key to a universal psychology, wherein cultural variants to theory are identified and cultural biases are appropriately minimized.

It should be recognized, however, that the results of this study are subject to a major limitation. Similar to the findings of Buetler et al. (1996), it was found that nearly $40 \%$ of the studies reviewed failed to report the ethnicity of participants. Hence the results of this study suffer from problems related to external validity (irony noted). It is possible that ethnicity was not reported in many studies because the samples were predominantly or exclusively Caucasian. However, because so many data are missing, this interpretation is speculative.

Given the wide variability across the journals in the reporting of ethnic information (see Table 1), efforts to enhance external validity are perhaps best made at the level of manuscript review. While it is encouraging that editors of APA journals have begun to address this issue (Azar, 1999), the discourse must initiate widespread change in editorial practice. In this regard, Beutler et al.'s (1996) recommendations remain the standard to which the field should adhere: If we are to substantially increase our knowledge about "what works with whom," ethnicity should 
consistently be treated like any other construct in the social sciences. To report detailed information regarding ethnicity is therefore only the bare minimum standard. Strength of ethnic identification and variables that have been found to mediate the effects of ethnicity, such as individualism/collectivism (Triandis, 1996), can be analyzed in relation to the results of a study. The burden of proof of external validity therefore shifts from those conducting ethnic minority research to all professionals publishing their work (Sue, 1999). Such burden is not a "politically correct" subjugation of scientific practice to the tenets of multiculturalism; it is simply "walking the talk" of good science. 


\section{References}

Alvidrez, J., Azocar, F., \& Miranda, J. (1996). Demystifying the concept of ethnicity for psychotherapy researchers. Journal of Consulting and Clinical Psychology, 64, 903-908.

American Counseling Association (1995). ACA Code of Ethics and Standards of Practice. Baltimore, MD: American Counseling Association.

American Psychological Association. (1992). Ethical principles of psychologists and code of conduct. American Psychologist, 47, 1597-1611.

American Psychological Association. (1997). Journals in psychology: A resource listing for authors. Washington, DC: American Psychological Association.

Azar. B. (1999, February). Journal editors find consortium helps researchers shape goals. APA Monitor, 20.

Babbie, E. (1998). The practice of social research ( $8^{\text {th }}$ ed.). Boston: Wadsworth.

Beutler, L.E. (1996). The view from the rear: An editorial. Journal of Consulting and Clinical Psychology, 64, 845-847.

Beutler, L. E., Brown, M. T., Crothers, L., Booker, K., \& Seabrook, M. K. (1996). The dilemma of factitious demographic distinctions in psychological research. Journal of Consulting and Clinical Psychology, 64, 892-902.

Graham, S. (1992). "Most of the subjects were white and middle class": Trends in published research on African Americans in selected APA journals, 1970-1989. American Psychologist, 47, 629-639.

Griffith, E. H., \& Baker, F. M. (1993). Psychiatric care of African Americans. In A. C. Gaw (Ed.), Culture, ethnicity and mental illness (pp. 147-173). Washington, DC: American Psychiatric Press.

Hooks, P. C., Tsong, Y., Henske, J. C., Baranowski, T., \& Levin, J. S. (1986). Social networking as a recruitment strategy for Mexican American families in community health research. Hispanic Journal of Behavioral Sciences, 8, 345-355. 
Hough, R. L., Landsverk, J. A., Karno, M., Burnam, M. A., Timbers, D. M., Escobar, J. I., \& Regier, D. A. (1987). Utilization of health and mental health services by Los Angeles Mexican Americans and non-Hispanic Whites. Archives of General Psychiatry, 44, 702-709.

Iwamasa, G. Y., \& Smith, S. K. (1996). Ethnic diversity in behavioral psychology: A review of the literature. Behavior Modification, 20, 45-59.

Maultsby, M. C. (1982). A historical view of Blacks' distrust of psychiatry. In S. M. Turner \& R. T. Jones (Eds.), Behavior modification in Black populations: Psychosocial issues and empirical findings. New York: Plenum.

Meinhardt, K., \& Vega, W. (1987). A method for estimating underutilization of mental health services by ethnic groups. Hospital and Community Psychiatry, 38, 1186-1190.

Mezzich, J. E., Ruiz, P. \& Munoz, R. A. (1999). Mental health care for Hispanic Americans: A current perspective. Cultural Diversity and Ethnic Minority Psychology, 5, 91-102.

Miranda, J. (1996). Introduction to the special section on recruiting and retaining minorities in psychotherapy research. Journal of Consulting and Clinical Psychology, 64, 848-850.

Miranda, J., Azocar, F., Organista, K. C., Munoz, R. F., \& Lieberman, A. (1996). Recruiting and retaining low-income Latinos in psychotherapy research. Journal of Consulting and Clinical Psychology, 64, 868-874.

National Association of School Psychologists. (1997). Principles for professional ethics. Bethesda, MD: NASP Publications.

National Institutes of Health. (1994). NIH guidelines on the inclusion of women and $\underline{\text { minorities as subjects in clinical research. }}$ 59, Fed. Reg. 14, 508 (Document no. 94-5435).

Neal, A. M., \& Turner, S. M. (1991). Anxiety disorders research with African Americans: Current status. Psychological Bulletin, 109, 400-410.

Santos de Barona, M. (1993). The availability of ethnic materials in psychology journals: A review of 20 years of journal publication. Contemporary Educational Psychology, 18, 391-400.

Schur, C. L., \& Albers, L. A. (1996). Language, sociodemographics, and health care use of hispanic adults. Journal of Health Care for the Poor and Underserved, 7, 140-158. 
Snowden, L. R., \& Cheung, F. K. (1990). Use of inpatient mental health services by members of ethnic minority groups. American Psychologist, 45, 347-355.

Sue, D. W., \& Sue, D. (1999). Counseling the culturally different: Theory and practice ( ${ }^{\text {rd }}$ ed.). New York: Wiley.

Sue, S. (1999). Science, ethnicity, and bias: Where have we gone wrong? American Psychologist, 54, 1070-1077.

Triandis, H. C. (1996). The psychological measurement of cultural syndromes. American Psychologist, 51, 407-415.

U.S. Bureau of the Census (1996). Statistical abstracts of the United States (116th ed.). Washington, DC: U.S. Government Printing Office.

Wells, K. B., Hough, R. L., Golding, J. M., Burnam, M. A. \& Karno, M. (1987). Which Mexican Americans underutilize health services? American Journal of Psychiatry, 144, 918-922.

Williams, D. H. (1986). The epidemiology of mental illness in Afro-Americans. Hospital and Community Psychiatry, 37, 42-49.

Yutrzenka, B. A. (1995). Making a case for training in ethnic and cultural diversity in increasing treatment efficacy. Journal of Consulting and Clinical Psychology, 63, 197-206. 
Table 1

Reporting Rates of Psychology Journals Reviewed.

\begin{tabular}{ll}
\hline & \\
Journal & Percentage of \\
& Research Articles \\
& Reporting Participant \\
& Ethnicity \\
\hline
\end{tabular}

\section{Clinical Psychology}

$\begin{array}{ll}\text { Journal of Abnormal Psychology } & 60.0\end{array}$

Journal of Clinical Child Psychology $\quad 78.6$

Journal of Clinical Psychology $\quad 59.8$

Journal of Consulting and Clinical Psychology 69.4

Professional Psychology: Research and Practice $\quad 37.0$

\section{Counseling Psychology}

$\begin{array}{lr}\text { Counseling Psychologist } & 65.0\end{array}$

Counselor Education and Supervision $\quad 54.0$

Journal of Counseling and Development $\quad 56.8$

Journal of Counseling Psychology $\quad 82.1$

\section{$\underline{\text { School Psychology }}$}

Journal of Instructional Psychology 33.3

Journal of School Psychology 59.5

Psychology in the Schools $\quad 61.9$

School Psychology Review $\quad 57.6$

The School Counselor $\quad 37.0$ 
Table 2

Percentages of Ethnic Groups in Psychology Research Samples Compared with U.S. Census

Data.

\begin{tabular}{lll}
\hline & & \\
& & \\
& & \\
& & \\
& Sesearch & U.S. Census \\
& & \\
\hline & & \\
People of Color & $25.9 \%$ & $26.3 \%$ \\
African American & $16.4 \%$ & $12.0 \%$ \\
Hispanic / Latino origin & $5.7 \%$ & $10.3 \%$ \\
Asian / Pacific Islander & $2.8 \%$ & $3.3 \%$ \\
American Indian & $1.1 \%$ & $0.7 \%$ \\
European American (White) & $74.1 \%$ & $73.6 \%$ \\
\hline
\end{tabular}

Note: Percentages for research sample composition are those with "other" and "international” participants eliminated from analyses. Census data are from the U.S. Bureau of Census, 1996. 